\title{
Comportamento da cultura do tomateiro sob diferentes tensões de água no solo em ambiente protegido ${ }^{1}$
}

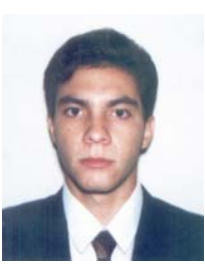

\author{
Nelson S. A. de Sá ${ }^{2}$, Geraldo M. Pereira ${ }^{3}$, Marco A. R. Alvarenga ${ }^{3}$, \\ Wesley Mattioli ${ }^{3} \&$ Jacinto de A. Carvalho ${ }^{3}$
}

\footnotetext{
${ }^{1}$ Parte da Dissertação de Mestrado do primeiro autor apresentada na Universidade Federal de Lavras; trabalho financiado pelo CNPq e CAPES

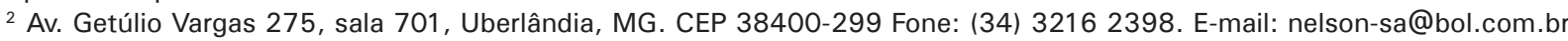
${ }^{3}$ UFLA, Lavras, MG, CEP 37200-000. Fone: (35) 3829 1389. E-mail: geraldop@ufla.br; marcoant@ufla.br; wesleym@uai.com.br
}

Protocolo 38 - 5/9/2003 - Aprovado em 4/3/2005

\begin{abstract}
Resumo: A cultura do tomateiro corresponde a uma atividade expressiva no Brasil, bastante exigente em água e, sob cultivo protegido, a irrigação deve ser usada para o suprimento hídrico total. O manejo adequado da irrigação é importante não apenas por suprir as necessidades hídricas das plantas mas, também, por minimizar problemas com doenças e lixiviação de nutrientes, além de gastos desnecessários com água e energia. Visando definir critérios para o manejo da irrigação, avaliou-se, através deste trabalho, o efeito de diferentes tensões de água no solo sobre o comportamento produtivo do tomateiro de crescimento indeterminado, híbrido Raísa $\mathrm{N}$, em ambiente protegido, na região de Lavras, MG. O experimento foi instalado em casa de vegetação com delineamento em blocos casualizados, tendo quatro repetições. Os tratamentos foram constituídos de seis níveis de tensões de água no solo como indicativos do momento de irrigar. As tensões preestabelecidas foram 15, 30,50,70, 120 e $170 \mathrm{kPa}$ e os resultados permitiram concluir-se que, para a obtenção de maiores produtividades de frutos totais, frutos comerciais e menor incidência de frutos com podridão apical, as irrigações devem ser realizadas quando as tensões de água no solo a $0,10 \mathrm{~m}$ de profundidade estiverem em torno de $80 \mathrm{kPa}$. Também foi possível observar que a eficiência no uso da água apresentou resposta linear crescente com o aumento da tensão de água no solo.
\end{abstract}

Palavras-chave: Lycopersicon esculentum, irrigação por gotejamento, manejo da irrigação, estresse hídrico

\section{Behavior of tomato crop under different soil water tensions in a greenhouse}

\begin{abstract}
The tomato crop corresponds to an expressive activity in Brazil, being a quite demanding crop in water and under greenhouse conditions the irrigation should be used for the total water supply. The appropriate irrigation management is not only an important factor to supply plant's water needs, but also to minimize problems with diseases, nutrient leaching as well as unnecessary expenses with water and energy. The purpose of this work was to evaluate the effect of different soil water tensions on the productive behavior of the tomato hybrid Raísa N, crop with indeterminate growth under greenhouse in the region of Lavras, MG. The experiment was installed in a greenhouse in a randomized block design with four replications. Treatments were constituted of six soil water tensions as indicative of the watering moment. Preset tensions were 15, 30, 50, 70, 120 and $170 \mathrm{kPa}$. Results allowed to conclude that to obtain higher total and commercial productivity and smaller incidence of black spot, the irrigations should be done when the water tension at $0.10 \mathrm{~m}$ soil depth is around $80 \mathrm{kPa}$. It was also possible to observe that the efficiency of water use presented positive linear correlation with the water tension in the soil.
\end{abstract}

Key words: Lycopersicon esculentum, drip irrigation, irrigation scheduling, water stress 


\section{INTRODUÇÃO}

A cultura do tomateiro corresponde a uma atividade expressiva no Brasil, chegando a atingir, em 2002, pouco mais de 3,49 milhões de toneladas produzidas, cultivadas em cerca de 62,37 mil hectares. Esta marca posiciona o País entre os oito maiores produtores mundiais (Agrianual, 2003).

Em uma cultura capaz de produzir acima de $200 \mathrm{t} \mathrm{ha}^{-1} \mathrm{de}$ frutos em cultura tutorada e mais de $100 \mathrm{t} \mathrm{ha}^{-1} \mathrm{em}$ cultura rasteira, é elevada a exigência de água. A irrigação influencia não apenas a produtividade, mas, também, a qualidade dos frutos, inclusive reduz a incidência de anomalias fisiológicas (Filgueira, 2000).

Oliveira (1995) cita as vantagens do uso de ambientes fechados e semi-fechados no cultivo de plantas, esclarecendo que as casas de vegetação cobertas com plástico podem proporcionar maior proteção às plantas contra fenômenos climáticos adversos, tais como geadas, granizo, excesso de chuva, sol muito forte durante o dia e queda acentuada da temperatura durante a noite. Elas também reduzem a lixiviação do solo e promovem uma adequada proteção contra pragas e doenças, além de permitir que se obtenha uma produção duas ou três vezes maior que as obtidas em cultivos de campo, uma vez que as plantas cultivadas sob plástico não sofrem influência dos fatores negativos observados a céu aberto. O autor acrescenta que, na expansão dos cultivos de plantas ornamentais e hortaliças em estufas, tem-se buscado maior produtividade, melhor qualidade e barateamento de produtos, durante a entressafra.

Reis et al. citado por Martins et al. (1999), verificaram, em Brasília, DF, que, de nove cultivares de tomate avaliadas, seis apresentaram maior rendimento em estufa (média de 52\%), em comparação com o cultivo no campo.

O manejo otimizado de irrigação requer uma estimativa sistemática da umidade no solo para determinar as quantidades apropriadas à planta e o tempo de irrigação para fornecê-la. $\mathrm{O}$ conteúdo de água do solo deve ser mantido entre certos limites superior e inferior específicos, em que a água disponível para a planta não é limitada, enquanto a lixiviação é prevenida (Morgan et al., 2001), sendo a reposição de água ao solo por irrigação, na quantidade e no momento oportuno, decisiva para o sucesso da horticultura (Marouelli et al., 1996).

Segundo Alvarenga (2000) a demanda máxima de água pelo tomateiro ocorre durante a floração e o crescimento dos frutos. A irrigação excessiva durante o período de floração, entretanto, tem provocado aumento na queda de flores e redução no estabelecimento de frutos, o que pode causar, também, crescimento vegetativo excessivo, atraso na maturação e maior ocorrência de doenças. Marouelli et al. (1996) apresentam as tensões de água no solo em que se deve promover a irrigação para se obter a produtividade máxima em diversas hortaliças; ressalva-se, todavia, que os valores apresentados devem ser adotados com reserva, caso a irrigação seja feita por gotejamento; neste caso, as culturas irrigadas apresentam melhor desempenho quando submetidas a tensões inferiores àquelas consideradas satisfatórias para outros sistemas.

Dentre as dificuldades que os produtores de tomate têm encontrado ao adotarem o cultivo em ambiente protegido, destaca-se a falta de informações específicas sobre qual o momento adequado de iniciar a irrigação e quanto de água aplicar nesta cultura e, assim sendo, na maioria das vezes a irrigação neste ambiente está sendo feita baseada somente no senso prático do irrigante, podendo resultar num aumento dos custos de produção (uso de energia e água, desnecessariamente) e queda da produtividade (água em excesso ou com déficit), devido ao manejo inadequado da irrigação.

Neste sentido, este trabalho teve como objetivo avaliar o efeito de diferentes tensões da água no solo sobre o comportamento produtivo do tomateiro, híbrido Raísa N, cultivada em ambiente protegido na região de Lavras, MG, visando definir critérios para o manejo da irrigação.

\section{MATERIAL E MÉTODOS}

O experimento foi desenvolvido em casa de vegetação situada na área experimental do Departamento de Engenharia da Universidade Federal de Lavras (UFLA), no período compreendido entre os meses de outubro de 2002 a fevereiro de 2003. A UFLA situa-se em Lavras, sul de Minas Gerais, e está numa altitude média de $910,0 \mathrm{~m}, 21^{\circ} 14^{\prime} \mathrm{S}$ e $45^{\circ} 00^{\prime} \mathrm{W}$. De acordo com a classificação de Köppen, a região apresenta clima $\mathrm{Cwb}$, ou seja, clima temperado suave, chuvoso, com inverno seco, temperatura média do mês mais frio inferior a $18^{\circ} \mathrm{C}$ e superior a $3{ }^{\circ} \mathrm{C}$ e o verão apresenta temperatura média do mês mais quente superior a $22^{\circ} \mathrm{C}$.

A casa de vegetação foi construída com estrutura metálica do tipo teto em arco, apresentando 3,00 $\mathrm{m}$ de pé-direito, 4,50 m de altura no ponto mais alto, $30 \mathrm{~m}$ de comprimento e $7 \mathrm{~m}$ de largura $\left(210 \mathrm{~m}^{2}\right)$. Foi revestida, na parte superior, com filme plástico transparente aditivado anti-UV de $0,15 \mathrm{~mm}$ de espessura e, nas laterais, com tela antiafídeos.

O solo foi classificado como Latossolo Vermelho Distroférrico (EMBRAPA, 1999). Amostras indeformadas foram coletadas nas profundidades de 0 a $0,20 \mathrm{~m} \mathrm{e} 0,20$ a $0,40 \mathrm{~m}$ para determinação da curva característica da água no solo e, a seguir, os valores encontrados foram ajustados (Eqs. 1 e 2, respectivamente) ao modelo proposto por van Genuchten (1980). A tensão de 10,0 kPa foi considerada correspondente à umidade na capacidade de campo (Carvalho et al., 1996).

$$
\begin{aligned}
& \theta_{0-0,2 \mathrm{~m}}=0,248+\frac{0,348}{\left[1+(0,5166 \times \psi)^{5,7936}\right]^{0,1394}} \\
& \theta_{0,2-0,4 \mathrm{~m}}=0,266+\frac{0,262}{\left[1+(0,5165 \times \psi)^{6,4126}\right]^{0,1300}}
\end{aligned}
$$

em que:

$$
\begin{aligned}
& \mathrm{e} \text { - umidade atual, } \mathrm{cm}^{3} \mathrm{~cm}^{-3} \\
& \varnothing \text { - tensão de água no solo, } \mathrm{kPa}
\end{aligned}
$$

O delineamento utilizado foi o de blocos casualizados com seis tratamentos e quatro repetições. Os tratamentos foram as tensões da água no solo correspondentes a $15\left(\mathrm{~T}_{1}\right), 30\left(\mathrm{~T}_{2}\right), 50$ 
$\left(\mathrm{T}_{3}\right), 70\left(\mathrm{~T}_{4}\right), 120\left(\mathrm{~T}_{5}\right)$ e $170\left(\mathrm{~T}_{6}\right)$ em $\mathrm{kPa}$, determinadas por sensores instalados a $0,10 \mathrm{~m}$ de profundidade. Para tal, instalouse uma bateria de nove tensiômetros de punção (três a $0,10 \mathrm{~m}$ de profundidade, três a $0,30 \mathrm{~m}$ e três a $0,40 \mathrm{~m}$ ) para monitorar as tensões de 15 a $70 \mathrm{kPa}$, e outra bateria de sensores de matriz granular (Granular Matrix Sensor-GMS, Watermark ${ }^{\circledR}$ - 200 SS), também contendo nove sensores (três na profundidade de 0,10 $\mathrm{m}$, três a $0,30 \mathrm{~m}$ e três a $0,40 \mathrm{~m}$ ) e sorteada entre as quatro parcelas de cada tratamento, para monitorar as tensões de 120 a $170 \mathrm{kPa}$. Tanto os tensiômetros quanto os sensores foram instalados no sentido de plantio, entre duas plantas e espaçados $0,15 \mathrm{~m}$ entre eles e as plantas. As parcelas experimentais apresentaram as dimensões de $1,20 \mathrm{~m}$ de largura e $3,00 \mathrm{~m}$ de comprimento $\left(3,60 \mathrm{~m}^{2}\right)$. Utilizaram-se duas linhas de plantas espaçadas $0,60 \mathrm{~m}$ entre si e $0,60 \mathrm{~m}$ entre plantas, totalizando 10 plantas por parcela. Foram consideradas úteis as plantas das linhas centrais, sendo descartadas uma planta no início e duas no final (parcela útil com $1,44 \mathrm{~m}^{2}$ e 4 plantas), ilustrado na Figura 1.

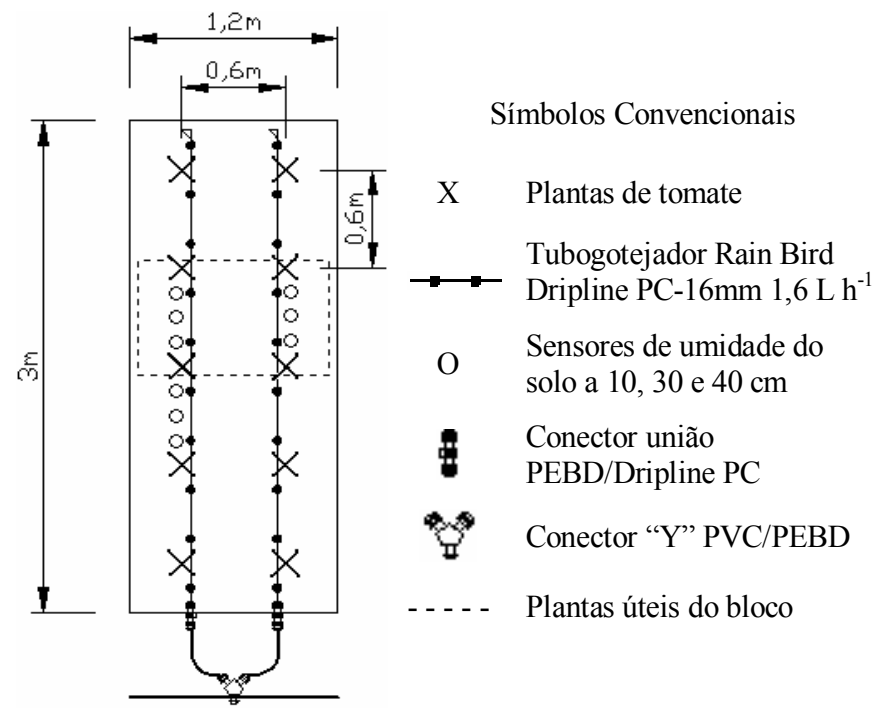

Figura 1. Esquema de uma parcela experimental com o sistema de irrigação implantado e os sensores de umidade

Utilizou-se sistema de irrigação por gotejamento, sendo as linhas laterais compostas por tubo gotejador com emissores de vazão de 1,6 $\mathrm{L} \mathrm{h}^{-1}$ para uma faixa de pressão entre 1 a $4 \mathrm{kgf}$ $\mathrm{cm}^{-2}$, espaçados a cada $0,30 \mathrm{~m}$, empregando-se dois gotejadores para cada planta. As linhas laterais foram conectadas diretamente às linhas principais de PVC que tinham, no início, válvulas de comando elétrico localizadas na saída do cabeçal de controle e utilizada uma válvula para cada tratamento. Essas válvulas eram acionadas por um controlador programável, funcionando o tempo necessário para a reposição da lâmina acusada, indiretamente, pelos sensores de umidade. Buscavase, em todas as irrigações, elevar a umidade do solo à capacidade de campo.

O cálculo do tempo de funcionamento do sistema de irrigação foi feito a partir da lâmina bruta média, calculada considerando-se a profundidade efetiva do sistema radicular igual a $0,40 \mathrm{~m}$ e estratificada em duas subcamadas $(0$ a $0,20 \mathrm{~m}$ e 0,20 a $0,40 \mathrm{~m}$ ). A subcamada de 0 a $0,20 \mathrm{~m}$ foi monitorada pelos sensores instalados a $0,10 \mathrm{~m}$ de profundidade e, na subcamada de 0,20 a $0,40 \mathrm{~m}$, os sensores foram instalados a $0,30 \mathrm{~m}$. A eficiência de aplicação de água do sistema foi determinada em $90 \%$. A partir da lâmina bruta total e dos valores de área ocupada por planta, número de emissores por planta e vazão média por emissor, chegava-se ao tempo de irrigação, de acordo com a Eq. 3.

$$
\mathrm{T}=\frac{\text { LB.Sp }}{\text { e.qa }}
$$

em que:

$\mathrm{T}$ - tempo de funcionamento do sistema de irrigação em cada tratamento, $\mathrm{h}$

LB - lâmina bruta total, mm, considerando-se as duas subcamadas estratificadas ( 0 a $0,20 \mathrm{~m}$ e 0,20 a $0,40 \mathrm{~m})$

Sp - área ocupada por planta, $0,36 \mathrm{~m}^{2}$

e - número de emissores por planta, 2

qa - vazão média dos emissores, $1,6 \mathrm{~L} \mathrm{~h}^{-1}$

O híbrido utilizado foi o Raísa N, classificado como tomate tipo saladinha, longa vida, de crescimento indeterminado. A adubação básica foi realizada dois dias antes do transplantio, tendo-se aplicado quantidades com base na análise química do solo e recomendações da $5^{\text {a }}$ aproximação (Gomes et al., 1999). Toda a adubação de cobertura foi feita via fertirrigação, dividindo-se o ciclo do tomateiro em três fases fenológicas, em que a primeira fase foi do transplante até o início do florescimento (0-30 DAT), a segunda do início do florescimento até início da colheita (31-72 DAT) e a terceira fase foi do início até o final da colheita (73-121 DAT) (Alvarenga, 2000).

Diante disso, e se seguindo as recomendações de Alvarenga (2000), parcelaram-se as aplicações de $\mathrm{Ne} \mathrm{K}_{2} \mathrm{O}$, sendo $20 \%$ na primeira fase, $30 \%$ na segunda fase e $50 \%$ na terceira fase. $\mathrm{O}$ cálcio foi aplicado $40 \%$ na segunda fase e $60 \%$ na terceira fase.

Do transplantio até o início da diferenciação dos tratamentos (15 DAT), foram feitas irrigações diárias repondose a lâmina evaporada do tanque Classe $\mathrm{A}$, aplicando-se 74,12 $\mathrm{mm}$ de água em cada tratamento com auxílio de um sistema de microaspersão, visando uniformizar o teor de umidade entre os tratamentos.

As variáveis analisadas foram produtividade de frutos de tomate, produtividade de frutos por classe de diâmetro (AAA $>60 \mathrm{~mm}, 60>\mathrm{AA}>56 \mathrm{~mm} \mathrm{e} 56>\mathrm{A}>46 \mathrm{~mm}$ ), produtividade de frutos rachados, porcentagem de frutos com podridão apical e eficiência no uso da água. A análise estatística dos dados incluíram-se a análise de variância com realização do teste $\mathrm{F}$, análises de regressão e comparação de médias pelo teste de Tukey a nível de 5 e 1\% de probabilidade (Gomes, 2000).

\section{RESULTADOS E DISCUSSÃO}

No período em que o experimento foi conduzido, a temperatura média do ar no interior da casa de vegetação era de $23,1^{\circ} \mathrm{C}$, as mínimas atingidas ficaram entre 12,9 e $22^{\circ} \mathrm{C}$ e as máximas entre 23,6 e $37,1^{\circ} \mathrm{C}$, resultando em uma diferença de $12,9{ }^{\circ} \mathrm{C}$ do dia para a noite. Essas temperaturas estão bem 
próximas do ideal para se cultivar tomate e, segundo Lopes \& Stripari (1998), é interessante observar a diferença de temperatura do dia e da noite, pois ocorre melhor crescimento quando a temperatura do dia está em torno de $26^{\circ} \mathrm{C}$ e a da noite em torno de 17 a $20^{\circ} \mathrm{C}$, ou seja, tendo-se uma diferença de 6 a $10^{\circ} \mathrm{C}$.

Os tratamentos de tensão apresentaram valores diferentes do estabelecido no início do experimento, de forma análoga a Figuerêdo (1998), apesar desses valores terem ficado próximos aos estabelecidos. O valor médio das tensões na profundidade de $0,10 \mathrm{~m}$ indicava o momento de irrigar, por caracterizar a faixa com maior quantidade de raízes e estar mais próximo da atmosfera; desta forma é a camada que seca mais rápido em relação às outras.

As lâminas de água aplicadas após o início da diferenciação dos tratamentos (Irrig) e os totais aplicados (Total), computados desde o transplantio da cultura, podem ser verificados na Tabela 1 . Nota-se que, quanto menor a tensão para que fossem iniciadas as irrigações, mais freqüentes foram as mesmas e maior foi a lâmina total aplicada. O mesmo comportamento foi obtido por Marouelli et al. (2003) e Santos (2002) em que a lâmina total de água aplicada decresceu com o incremento da tensão de água no solo, sendo menos freqüentes as irrigações e maior a lâmina de água por aplicação.

Tabela 1. Tensões da água no solo observadas no início das irrigações na profundidade de $0,10 \mathrm{~m}$, lâminas aplicadas após se diferenciar os tratamentos (Irrig), total (Total) e média por irrigação (mpi), intervalo médio entre irrigações (TR) e número de irrigações (NI)

\begin{tabular}{|c|c|c|c|c|c|c|}
\hline \multirow{2}{*}{ Trat } & \multirow{2}{*}{$\begin{array}{c}\text { Tensão } \\
(\mathrm{kPa})\end{array}$} & \multicolumn{3}{|c|}{ Lâmina (mm) } & \multirow{2}{*}{$\begin{array}{c}\mathrm{TR} \\
\text { (dia) }\end{array}$} & \multirow{2}{*}{ NI } \\
\hline & & Irrig & Total & mpi & & \\
\hline $\mathrm{T}_{1}$ & 15 & 624,7 & 698,8 & 8,8 & 1,5 & 72 \\
\hline $\mathrm{T}_{2}$ & 30 & 580,3 & 654,5 & 14,9 & 2,7 & 39 \\
\hline $\mathrm{T}_{3}$ & 50 & 496,9 & 571,0 & 17,7 & 3,7 & 28 \\
\hline $\mathrm{T}_{4}$ & 70 & 445,7 & 519,8 & 23,5 & 5,4 & 19 \\
\hline $\mathrm{T}_{5}$ & 120 & 195,2 & 269,3 & 24,4 & 12,1 & 8 \\
\hline $\mathrm{T}_{6}$ & 170 & 109,0 & 183,1 & 27,2 & 19,6 & 5 \\
\hline
\end{tabular}

A produtividade de frutos totais (PFT) e de frutos comerciais (PFC) foi altamente influenciada pelas diferentes tensões de água aplicadas no solo a nível de 1\% de probabilidade e, para esta variável, o delineamento em blocos casualizados não se mostrou eficiente. Portanto, não se justifica o controle local, ou seja, neste caso o delineamento poderia ser o inteiramente casualizado (Tabela 2); já na produtividade de frutos não comerciais (PFNC) não houve efeito dos tratamentos aplicados.

No caso da produtividade de frutos totais, as diferenças podem ser explicadas por uma regressão cúbica, a $5 \%$ de probabilidade. $\mathrm{O}$ ponto de máximo para esta variável ocorreu na tensão de $76,5 \mathrm{kPa}$, resultando em uma produtividade, para este parâmetro, de 104,3 $\mathrm{Mg} \mathrm{ha}^{-1}$.

Com relação à PFC, as diferenças podem ser explicadas por uma regressão quadrática, significativa a $1 \%$ de probabilidade, pois teve melhor ajuste que a regressão linear. O ponto de máximo para essa variável ocorreu na tensão de $83,3 \mathrm{kPa}$, resultando em uma produtividade de $83,6 \mathrm{Mg} \mathrm{ha}^{-1}$ para este parâmetro. Percebe-se, na Figura 2, que tensões de água no
Tabela 2. Resumo da análise de variância e de regressão para produtividade de frutos totais ( $\left.\mathrm{PFT} ; \mathrm{Mg} \mathrm{ha}^{-1}\right)$, produtividade de frutos comerciais (PFC; $\mathrm{Mg} \mathrm{ha}^{-1}$ ) e produtividade de frutos não comerciais (PFNC; $\mathrm{Mg} \mathrm{ha}^{-1}$ ) de plantas de tomate

\begin{tabular}{lcccc}
\multicolumn{1}{c}{$\begin{array}{c}\text { Fonte } \\
\text { de variação }\end{array}$} & G. L. & \multicolumn{3}{c}{ Q. M. } \\
\cline { 3 - 5 } Tensão & 5 & $59,43^{* *}$ & $60,49^{* *}$ & $7,93^{\mathrm{ns}}$ \\
Bloco & 3 & $10,38^{\mathrm{ns}}$ & $6,02^{\mathrm{ns}}$ & $9,04^{\mathrm{ns}}$ \\
Resíduo & 15 & 8,85 & 4,49 & 5,75 \\
Média & - & 100,21 & 80,94 & 19,28 \\
C. V. (\%) & - & 2,97 & 2,62 & 12,44 \\
Linear & 1 & $49,41^{\mathrm{ns}}$ & $39,91^{* *}$ & $0,51^{\mathrm{ns}}$ \\
Quadrática & 1 & $33,56^{\mathrm{ns}}$ & $120,44^{* *}$ & $26,85^{*}$ \\
Cúbica & 1 & $49,75^{*}$ & $29,77^{*}$ & $2,55^{\mathrm{ns}}$ \\
Desvios & 2 & $82,21^{* *}$ & $56,17^{* *}$ & $4,88^{\mathrm{ns}}$ \\
Resíduo & 15 & 8,85 & 4,49 & 5,75 \\
\hline${ }^{*}$ e 'Significativo a 1 e 5\% de probabilidade pelo teste F, respectivamente; ns Não significativo
\end{tabular}

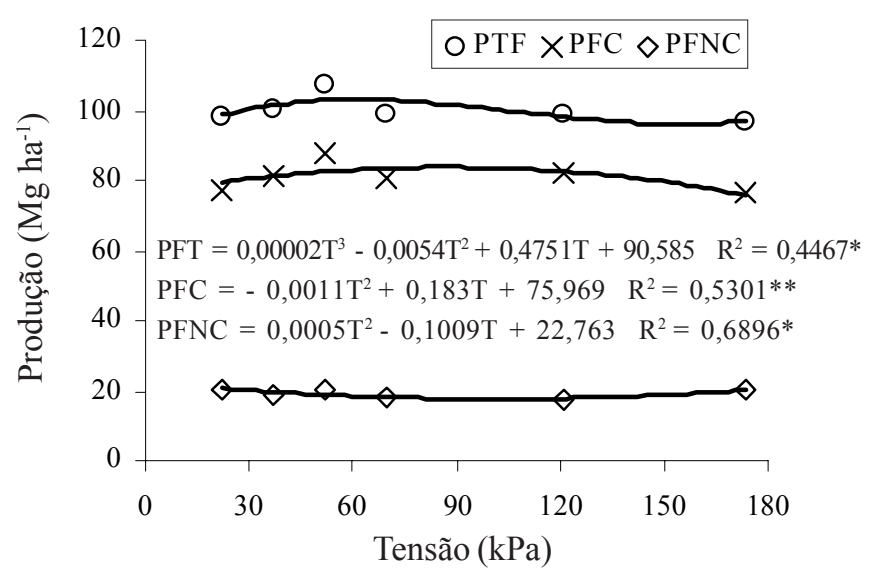

Figura 2. Produtividade de frutos totais (PFT), de frutos comerciais (PFC) e frutos não-comerciais (PFNC) sob influência de tensão de água no solo

solo muito abaixo ou muito acima de $83,3 \mathrm{kPa}$, aumentam a incidência de frutos não comerciais, indicando ter havido excesso e falta de água nessas tensões, respectivamente.

A produtividade de frutos classe AAA, AA e A, apresentou resposta quadrática e linear, significativa a 1 e $5 \%$ de probabilidade, pelo teste $\mathrm{F}$ (Tabela 3). A soma das produtividades de frutos classe AAA, AA e A compõe a produtividade de frutos comerciais, também presente na tabela abaixo para comparações.

A produtividade de frutos classe AAA seguiu a mesma tendência da produtividade de frutos comerciais e ambas podem ser explicadas por uma regressão quadrática, significativa a $1 \%$ de probabilidade. Tensões muito baixas e muito altas influenciaram negativamente, sendo a tensão de $112,4 \mathrm{kPa}$ obtida pela regressão, a que proporcionou maior produtividade de frutos classe AAA. Na Figura 3 observa-se o resultado da regressão para as três classes de tamanho de frutos e compará-los com a produtividade de frutos comerciais.

De forma oposta em relação ao parâmetro anterior, observase a produtividade de frutos classe AA, a qual foi influenciada a 5\% de probabilidade pelos tratamentos e cujo comportamento é descrito por uma regressão quadrática significativa a $5 \%$ de probabilidade. Percebe-se que em tensões de água no solo 
Tabela 3. Resumo da análise de variância e de regressão para produtividade de frutos comerciais (PFC; $\mathrm{Mg} \mathrm{ha}^{-1}$ ), produtividade de frutos classe AAA (AAA; $\left.\mathrm{Mg} \mathrm{ha}^{-1}\right)$, classe AA $\left(\mathrm{AA} ; \mathrm{Mg} \mathrm{ha}^{-1}\right)$ e classe $\mathrm{A}\left(\mathrm{A} ; \mathrm{Mg} \mathrm{ha}^{-1}\right)$ de plantas de tomateiro

\begin{tabular}{|c|c|c|c|c|c|}
\hline \multirow{2}{*}{$\begin{array}{c}\text { Fonte } \\
\text { de variação }\end{array}$} & \multirow{2}{*}{ G. L. } & \multicolumn{4}{|c|}{ Q. M. } \\
\hline & & PFC & AAA & $\mathrm{AA}$ & A \\
\hline Tensão & 5 & $60,49 * *$ & $166,31 * *$ & $8,25^{*}$ & $61,75^{*}$ \\
\hline Bloco & 3 & $6,02^{\mathrm{ns}}$ & $6,00^{\mathrm{ns}}$ & $1,30^{\mathrm{ns}}$ & $4,73^{\mathrm{ns}}$ \\
\hline Resíduo & 15 & 4,49 & 19,96 & 2,47 & 15,95 \\
\hline Média & - & 80,94 & 57,67 & 7,90 & 15,36 \\
\hline C. V. $(\%)$ & - & 2,62 & 7,75 & 19,88 & 26,00 \\
\hline Linear & 1 & $39,91 * *$ & $126,89 *$ & $7,98^{\mathrm{ns}}$ & $217,77 * *$ \\
\hline Quadrática & 1 & $120,44 * *$ & $363,03 * *$ & $19,80 *$ & $13,17^{\mathrm{ns}}$ \\
\hline Cúbica & 1 & $29,77^{*}$ & $74,11^{\mathrm{ns}}$ & $2,59^{\mathrm{ns}}$ & $2,38^{\mathrm{ns}}$ \\
\hline Desvios & 2 & $56,17 * *$ & $133,77 * *$ & $5,43^{\mathrm{ns}}$ & $37,71^{\mathrm{ns}}$ \\
\hline Resíduo & 15 & 4,49 & 19,96 & 2,47 & 15,95 \\
\hline
\end{tabular}

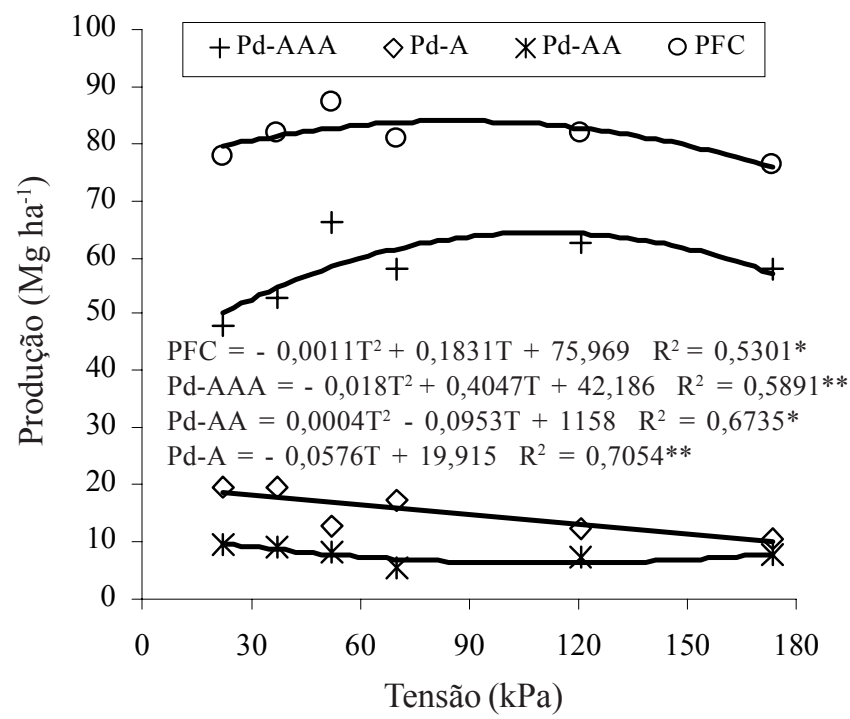

Figura 3. Produtividade de frutos comerciais (PCF), produtividade de frutos classe AAA (Pd-AAA), produtividade de frutos classe $\mathrm{AA}(\mathrm{Pd}-\mathrm{AA})$ e produtividade de frutos classe $\mathrm{A}(\mathrm{Pd}-\mathrm{A})$ sob influência de tensão de água no solo

acima ou abaixo de $119,1 \mathrm{kPa}$, pode haver aumento na produtividade desta classe de fruto.

A produtividade de frutos classe A seguiu uma regressão linear siginificativa a $1 \%$ de probabilidade, demonstrando haver diminuição de $57,6 \mathrm{~kg} \mathrm{ha}^{-1}$ com o aumento de $1 \mathrm{kPa}$ na tensão de água no solo. Desta forma, vê-se que, a uma tensão menor de água no solo, a produtividade de frutos grandes se reduz e há maior produtividade de frutos menores. Por outro lado, com alta tensão de água no solo, a produtividade de frutos grandes torna a reduzir, mas há poucos frutos pequenos e, com isso, a planta desloca suas reservas para a produção de frutos de maior diâmetro.

Macêdo (2002) observou aumento linear do número de frutos de tomate nas classes AAA, AA e A com a aplicação de $40,60,80$ e $100 \%$ da evapotranspiração da cultura, resultando em lâminas totais aplicadas de 178,1; 259,5; 339,4 e 419,2 mm.
Observa-se, ainda, que a lâmina mínima aplicada por este autor é bem próxima aos 183,1 mm (Tabela 1) aplicados neste experimento, resultando em um efeito semelhante para ambos os experimentos; no entanto, a lâmina máxima aplicada por este autor está bem abaixo dos 698,8 mm aplicados, o que corrobora para a diminuição da produtividade de frutos comerciais e de classe AAA, por excesso de água.

Verifica-se, na Tabela 4, efeito quadrático significativo de tensões de água no solo a $1 \%$ de probabilidade sobre a produtividade de frutos rachados. As oscilações no teor de água no solo aumentaram a incidência de frutos rachados até determinado valor, $80,9 \mathrm{kPa}$ e, a partir daí, com oscilações bruscas mas pouco freqüentes, constatou-se diminuição da ocorrência desse tipo de alteração fisiológica no fruto (Figura 4).

Ocorrem rachaduras nos frutos durante o período de maturação, quando há variações de umidade no solo reduzindo, assim, a produção de frutos comerciais (Daker, 1970; Filgueira, 2000).

Pilatti \& Paletto (1996) obtiveram redução significativa na percentagem de frutos rachados, devido à possibilidade de se reduzir a variação da umidade do solo utilizando-se "mulching"; assim, a adoção da cobertura plástica no solo, juntamente com

Tabela 4. Resumo da análise de variância e de regressão para produtividade de frutos rachados (PFR), porcentagem de frutos com podridão apical (\% PA) e eficiência no uso da água (EUA) de plantas de tomateiro

\begin{tabular}{lcccc}
\hline \multicolumn{1}{c}{$\begin{array}{c}\text { Fonte } \\
\text { de variação }\end{array}$} & G. L. & \multicolumn{3}{c}{ Q. M. } \\
\cline { 3 - 5 } Tensão & 5 & $10,03^{* *}$ & $0,0768^{*}$ & $95693,72^{* *}$ \\
Bloco & 3 & $0,71^{\mathrm{ns}}$ & $0,0508^{\mathrm{ns}}$ & $54,77^{\mathrm{ns}}$ \\
Resíduo & 15 & 1,99 & 0,0250 & 37,97 \\
Média & - & 14,16 & 0,4379 & 261,68 \\
C. V. (\%) & - & 9,97 & 36,11 & 2,35 \\
Linear & 1 & $5,88^{\mathrm{ns}}$ & $0,1218^{*}$ & $464984,07^{* *}$ \\
Quadrática & 1 & $22,76^{* *}$ & $0,2522^{* *}$ & $8791,43^{* *}$ \\
Cúbica & 1 & $21,47^{* *}$ & $0,0094^{\mathrm{ns}}$ & $2056,57^{* *}$ \\
Desvios & 2 & $0,03^{\mathrm{ns}}$ & $0,0003^{\mathrm{ns}}$ & $1318,28^{* *}$ \\
Resíduo & 15 & 1,99 & 0,0250 & 37,97 \\
\hline
\end{tabular}

* e " Significativo a 1 e $5 \%$ de probabilidade pelo teste F, respectivamente; ${ }^{\text {ns }}$ Não significativo

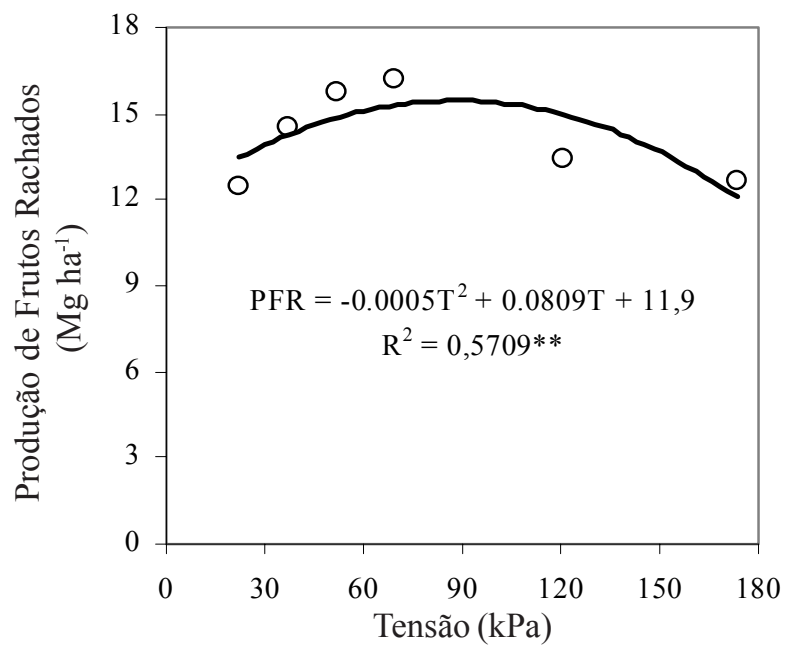

Figura 4. Produtividade de frutos rachados sob influência de tensão de água no solo 
a alta freqüência da irrigação utilizada pelos autores citados, pode ter influenciado na atenuação da incidência de frutos rachados.

A porcentagem de frutos com podridão apical $(\% \mathrm{PA})$ neste experimento foi, no geral, de baixa intensidade, ou seja, menor que $1 \%$, o que sugere menor sensibilidade do híbrido Raísa $\mathrm{N}$ à deficiência de cálcio. Houve influência da tensão de água no solo, a $1 \%$ de probabilidade, descrevendo um comportamento quadrático (Tabela 4).

A podridão apical consiste numa mancha preta, deprimida, coriácea, seca e firme no ápice do fruto (Alvarenga, 2000) e está, geralmente, associada à deficiência localizada de cálcio nesses tecidos (Filgueira, 2000), deficiência hídrica e excesso de sais no solo (Alvarenga, 2000).

Houve tendência de maior ocorrência de podridão apical em plantas submetidas a baixos e altos níveis de tensão de água no solo; tanto o excesso quanto a falta de água prejudicam a absorção de cálcio pela planta.

Ocorre menor incidência desse distúrbio fisiológico quando as plantas de tomateiro são submetidas a uma tensão média de água no solo de $81,0 \mathrm{kPa}$ (Figura 5).

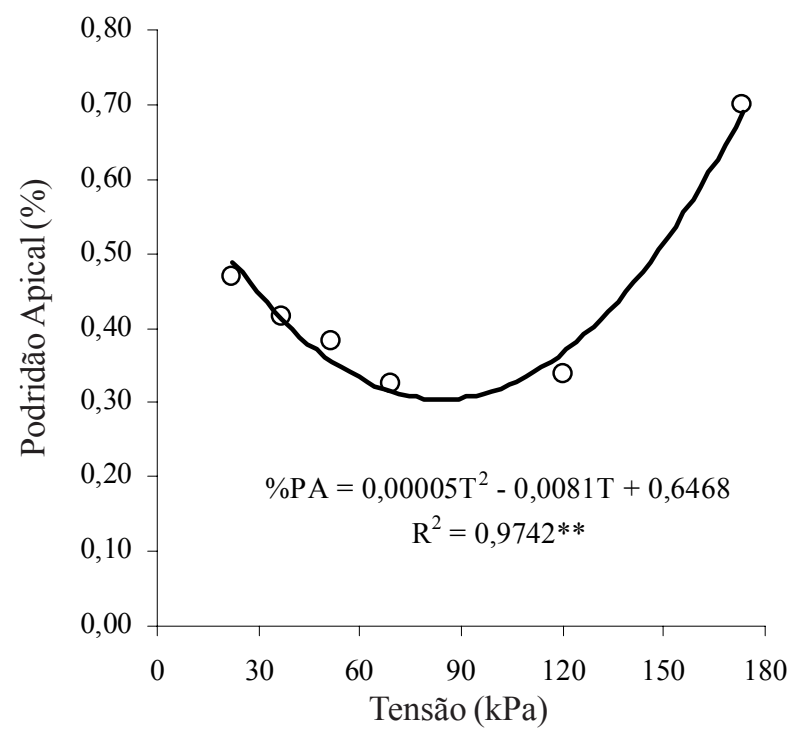

Figura 5. Porcentagem da produtividade total de frutos com ocorrência de podridão apical sob influência de tensão de água no solo

Segundo Papadopoulos (1991), na maioria dos casos a deficiência de cálcio na planta é induzida, sendo a principal causa o estresse de água na planta devido a irrigações deficitárias ou excessivas.

A eficiência do uso de água (EUA) apresentou correlação linear positiva (Figura 6) com a tensão de água no solo durante o ciclo do tomateiro, a $1 \%$ de significância, como pode ser observado na Tabela 4.

Resultado semelhante foi obtido por Marouelli et al. (2003) em tomateiro submetido a tensões de água no solo durante a fase vegetativa, não se constatando diferenças ocasionadas por tensões entre 15 e $70 \mathrm{kPa}$ aplicadas no estádio de frutificação.

Coelho et al. (1994) também observaram que a eficiência do uso da água apresentou valores decrescentes com o aumento

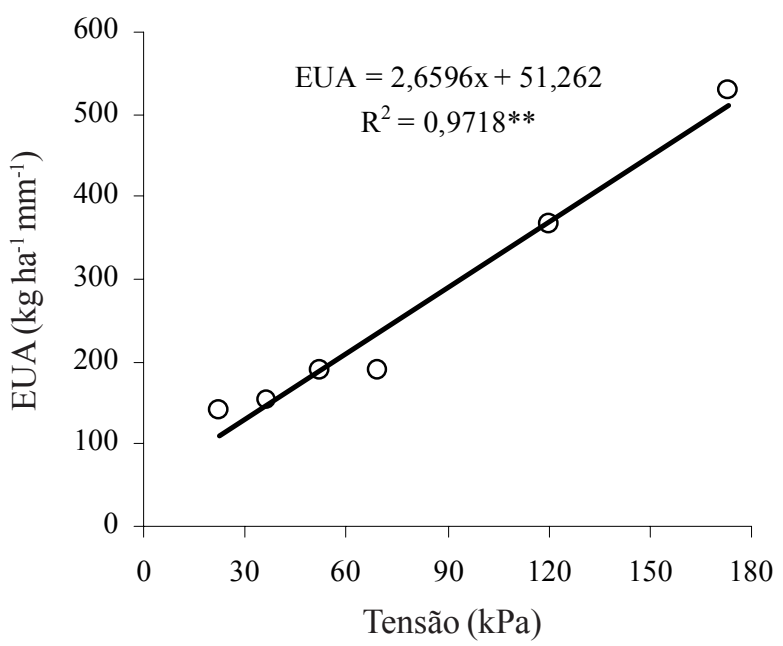

Figura 6. Eficiência do uso de água (EUA; $\mathrm{kg} \mathrm{ha}^{-1} \mathrm{~mm}^{-1}$ ) em plantas de tomateiro submetidas a diferentes níveis de tensão de água no solo

da lâmina d'água aplicada, porém a maior receita líquida foi obtida com a aplicação da maior lâmina, resultado do incremento na produtividade obtida.

\section{CONCLUSÕES}

1. Para a obtenção de maiores produtividades de frutos totais e frutos comerciais e menor incidência de frutos com podridão apical, as irrigações devem ser realizadas quando as tensões de água no solo a $0,10 \mathrm{~m}$ de profundidade, estiverem em torno de $80 \mathrm{kPa}$.

2. A produtividade de frutos classe A (frutos pequenos) reduz com o aumento da tensão, enquanto a produtividade de frutos classe AAA (frutos grandes) é máxima na tensão de $112 \mathrm{kPa}$.

3. A produtividade de frutos rachados é máxima na tensão de $81 \mathrm{kPa}$.

4. Para valores menores e maiores que $81 \mathrm{kPa}$, há menor variação da umidade do solo ou variações menos freqüentes, diminuindo a incidência deste distúrbio fisiológico.

5. A eficiência no uso da água apresentou resposta linear crescente com o aumento da tensão de água no solo.

\section{AGRADECIMENTOS}

Ao Conselho Nacional de Desenvolvimento Científico e Tecnológico - CNPq, e à Fundação de Amparo à Pesquisa do Estado de Minas Gerais - FAPEMIG, pelo auxílio financeiro concedido e, ainda, ao Departamento de Engenharia da UFLA.

\section{LITERATURA CITADA}

Agrianual - Anuário da Agricultura Brasileira. Tomate. São Paulo: FNP, 2003. p.515-522.

Alvarenga, M.A.R. Cultura do tomateiro. Lavras: UFLA, 91p. 2000. Textos Acadêmicos 2

Carvalho,L.G. de; Sampaio, S.C.; Silva, A.M. da. Determinação da umidade na capacidade de campo in situ de um Latossolo Roxo distrófico. Engenharia Rural, Piracicaba, v.7, n.1, p.197, 1996. 
Coelho, E.F.; Souza, V.A.B. de; Conceição, M.A.F; Duarte, J. de O. Comportamento da cultura do tomateiro sob quatro regimes de irrigação. Pesquisa Agropecuária Brasileira. Brasília, v.29, n.12, p.1959-1968, 1994.

Daker, A. Água na agricultura: irrigação e drenagem. 3.ed. Rio de Janeiro: Livraria Freitas Bastos, 1970. v.3, 453p.

EMBRAPA. Centro Nacional de Pesquisa de Solos. Sistema brasileiro de classificação de solos. Rio de Janeiro: Embrapa Solos, 1999. 412p.

Figuerêdo, S.F. Estabelecimento do momento de irrigação com base na tensão de água no solo para a cultura do feijoeiro. Piracicaba: ESALQ/USP, 1998. 94p. Dissertação Mestrado

Filgueira, F.A.R. Novo manual de olericultura: agrotecnologia moderna na produção e comercialização de hortaliças. Viçosa: UFV, 2000.402p.

Gomes, F.P. Curso de estatística experimental. 14. ed. Piracicaba: ESALQ/USP, 2000.477p.

Gomes, L.A.A.; Silva, E.C. da; Faquin, V. Recomendações de adubação para cultivos em ambiente protegido. In: Ribeiro, A.C.; Guimarães, P.T.G.; Alvarez, V.V.H. (ed.). Recomendações para o uso de corretivos e fertilizantes em Minas Gerais: $5^{\text {a }}$ aproximação. Viçosa: 1999. p.99-110.

Lopes, M.C.; Stripari, P.C. A cultura do tomateiro. In: Goto, R.; Tibelli, S.W. Produção de hortaliças em ambiente protegido: condições subtropicais. São Paulo: Fundação Editora da UNESP, 1998. p.257-319.

Macêdo, L. de S. Lâminas de água e fertirrigação potássica sobre o crescimento, produção e qualidade de frutos do tomateiro (Lycopersicon esculentum Mill.) em ambiente protegido. Lavras: UFLA, 2002. 101p. Tese Doutorado
Marouelli, W.A.; Silva, W.L.C.; Moretti, C.L. Resposta do tomateiro para processamento a tensões de água no solo, sob irrigação por gotejamento. Engenharia Agrícola, Jaboticabal, v.23, n.1, p.1-8, 2003.

Marouelli, W.A.; Silva, W.L. de C.E.; Silva, H.R. da. Manejo da irrigação em hortaliças. 5.ed. Brasília: EMBRAPA-SPI, 1996. $72 \mathrm{p}$.

Martins, S.R.; Fernandes, H.S.; Assis, F.N.; Mendez, M.E.G. Caracterização climática e manejo de ambientes protegidos: a experiência brasileira. Informe Agropecuário, Belo Horizonte, v.20, n.200/201, p.15-23, 1999.

Morgan, K.T.; Parsons, L.R; Wheaton, T.A. Comparison of laboratory - and field - derived soil water retention curves for a fine sand soil using tensiometric resistance and capacitance methods. Plant and Soil. Dordrecht, v.234, n.2, p.153-157, 2001 .

Oliveira, M.R.V. O emprego de casas de vegetação no Brasil: vantagens e desvantagens. Pesquisa Agropecuária Brasileira, Brasília, v.30, n.8, p.1049-1060, 1995.

Papadopoulos, A.P. Growing greenhouse tomatoes in soil and in soilless media. Ontario: Communications Branch, Agriculture Canada. 1991. 79p.

Pilatti, R.A.; Paletto, C.H. Effect of mulching and shading on splitting of tomato fruits grown in the greenhouse. Horticultura Argentina, v.15, n.38, p.12-16, 1996.

Santos, D. S. dos. Efeitos da tensão de água no solo, na cultura do pepino (Cucumis sativus L.) utilizando sistema de irrigação automatizado. Lavras:UFLA, 2002. 60p. Dissertação Mestrado

van Genuchten, M. TH. A closed-form equation for predicting the hydraulic conductivity of unsaturated soils. Soil Science Society America Journal, Madison, v.44, n.5, p.892-898, 1980. 